\title{
EFFECT OF VARIOUS PH MEDIA ON FRACTURE TOUGHNESS AND HARDNESS OF BI-LAYERED REINFORCED POLYMER AND MONO- LITHIC HYBRID CERAMICS
}

\author{
Nagy M Omar ${ }^{*}$,Hussein R Mohammed ${ }^{* *}$, Khalid M Hagag ${ }^{* * *}$
}

\begin{abstract}
Objective: This study evaluated the effect of various $\mathrm{pH}$ media on fracture toughness and hardness of bi-layered reinforced polymer and monolithic hybrid ceramics.

Materials and Methods: A total of 80 samples were used in this study. Samples were divided into two main groups according to the material used, Poly Ether Ether Ketone (PEEK) group (40 samples) and Vita Enamic group (40 samples). Each group was subdivided into 4 subgroups according to PH media used into: control group, strong acid medium (Pepsi), weak acid medium (coffee), and distilled water. Testing was performed before and after 24 days of $\mathrm{pH}$ media storage. Data were statistically analyzed using Student t-test, paired t-test with the significance level set at $\mathrm{p} \leq 0.05$.
\end{abstract}

Results: Hardness results irrespective to material type: it was found that baseline subgroup recorded statistically significant highest hardness, followed by $p H 5.5$ subgroup, then $p H 7$ subgroup, while $p H 2.5$ subgroup recorded statistically significant lowest hardness. Fracture toughness results irrespective to material type: it was found that baseline subgroup recorded the statistically significant highest fracture toughness, followed by $p H 7$ subgroup, then $p H 2.5$. Subgroup, while $p H 5.5$ subgroup recorded the statistically significant lowest fracture toughness.

Conclusion: PEEK material recorded higher fracture toughness mean value than Vita Enamic, while Vita Enamic material recorded higher hardness mean value than PEEK. Both materials were affected more by $\mathrm{pH} 2.5$ (Pepsi), followed by $\mathrm{pH} 5.5$ (coffee), then $\mathrm{pH} 7$ when measuring hardness. Both materials were affected more by pH5.5 (coffee), followed by pH2.5 (Pepsi), then by $\mathrm{pH} 7$ when measuring fracture toughness.

Keywords: Micro hardness; Fracture toughness; Monolithic hybrid ceramic: PEEK, CAD/CAM.

\section{INTRODUCTION}

Continuous developments in dentistry encourage the modification of materials to be similar to the natural tooth structure concerning mechanical and optical properties. Although ceramic materials have excellent esthetic requirements, they encounter different disadvantages such as brittleness and wearing to opposing natural teeth ${ }^{(1)}$. Accordingly, the polymers modification and incorporation with ceramic particles were done to overcome the inherent disadvantages of all ceramics. One of the polymers which is used in medical field is Poly Ether Ether Ketone(PEEK). It is used in orthopedics surgery for hip replacement because of tissue biocompatibility ${ }^{(2-4)}$. PEEK was modified for dental use as alternative to conventional metal framework and veneered by reinforced composite for optimum esthetics ${ }^{(5,6)}$. PEEK was reported to have good mechanical properties ${ }^{(4)}$, and modulus of elasticity similar todentine ${ }^{(7)}$.

\footnotetext{
* Demonstrator of Crown and bridge, Faculty of Dental Medicine for Boys ,Al-Azhar University .

** Lecture of Crown and bridge, Faculty of Dental Medicine for Boys, Al-Azhar University .

*** Professor of Crown and bridge, Faculty of Dental Medicine for Boys, Al-Azhar University .
} 
Monolithic form of a polymer-based restoration is also used in dentistry as Vita Enamic, which is a hybrid dental ceramic with a dual-network structure, where the dominant porous sintered feldspathic ceramic network is strengthened by a methacrylate polymeric network. Vita Enamic was reported to have high flexural strength values an elasticity resembling dentin and the ability to acquire high strength after adhesive bonding and therefore, minimal invasive restorations are possible ${ }^{(8,9)}$.

Hardness and fracture toughness are important factors influencing the clinical long-term success of dental prostheses especially in high stress situations (10). The micro hardness of resinous materials has also been reported to be detrimentally affected by lengthy contact with coffee, tea, mouthwashes, acidic food and low $\mathrm{pH}$ drinks. Such softening might worsen its wear resistance and could lead to restoration failure due to fatigue ${ }^{(11,12)}$. The hypothesis of this study is that various $\mathrm{PH}$ media will affect hardness and fracture toughness before and after immersion.

\section{MATERIALS AND METHODS}

A total of 80 round-shaped samples were divided into two equal groups of 40 samples according to the type of material used, group P (PEEK) (Bredent GmbH \& Co.KG, Germany), and group V (Vita Enamic) (VITA Zahnfabrik H.Rauter GmbH \&Co. $\mathrm{KG})$. Each group was further subdivided into four equal subgroups, 10 samples each, according to $\mathrm{pH}$ media used: baseline subgroup, strong acid medium subgroup, weak acid medium subgroup, and neutral subgroup (Figure 1).

A total of 40 PEEK samples were milled, with each sample being composed of two layers; (substrate layer Bio HPP and the veneering layer was HIPC). One blank of Bio.HPP and one blank of Bio.HIPC were used to obtain cylinders with diameter of $(10 \mathrm{~mm})$ which were designed by a Computer software (Meshmixer 3.5), then milled by CADICAM milling machine (Arum 5x-400
Europe, GmbH, Frankfurt, Germany). These cylinders were cut to produce 40 discs of Bio.HPP (10mm diameter x $0.7 \mathrm{~mm}$ thickness) and 40 discs of veneering Bio.HIPC (10mm diameter x $0.8 \mathrm{~mm}$ thickness) with desired dimensions using Isomet cutting machine (Isomet 4000 linear precision saw, Lake Bluff, USA) (2500rpm with coolant). A digital caliper (Proskit Mechanical digital caliper) was used to ensure thickness and diameter of each sample.

A custom-made machine was constructed to hold the discs for micro etching of the veneering surface of Bio.Hpp discs and inner surface of HIPC were abraded with aluminum oxide powder with $110 \mu \mathrm{m}$ $\mathrm{Al}_{2} \mathrm{O}_{3}$ powder at pressure $0.25 \mathrm{MPa}$, at an angle of $45^{\circ}$ from a distance of $10 \mathrm{~mm}$ using micro etcher. All discs were then cleaned in an ultrasonic cleaner filled with distilled water for 5 minutes, then left to dry. PEEK discs were conditioned using Visio. Link for 1 minute, then polymerized for $90 \mathrm{~s}$ at $220 \mathrm{~mW} / \mathrm{cm}^{2}$ by polymerizing light cure machine. The veneers were applied by Compo.lign before pressing them on the substrate then excess cement was removed by brush before polymerization by a light cure machine for $180 \mathrm{~s}$ at $220 \mathrm{~mW} / \mathrm{cm}^{2}$ according to manufacturer's recommendations.

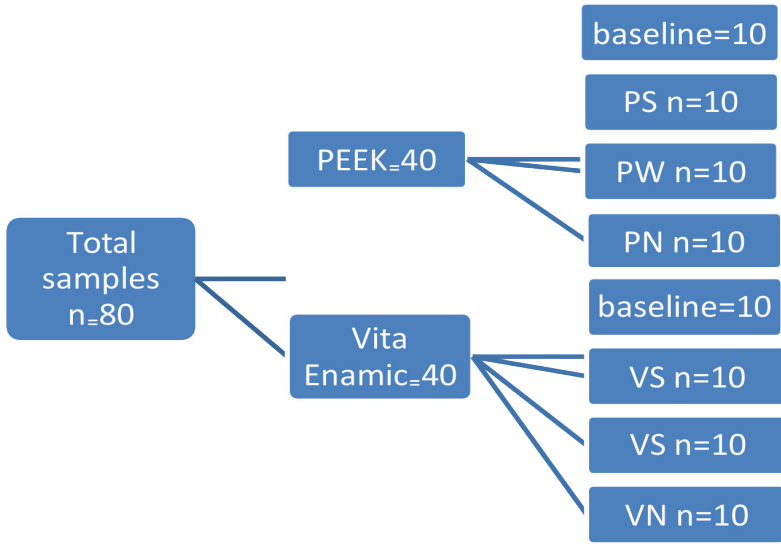

FIG (1) Diagram of Sample grouping

Using the same technique of PEEK, Vita Enamic blocks were milled by CAD /CAM machine to obtain cylinder block with round diameter then these blocks were cut by Isomet to obtain 30 round 
shaped samples with surface area of $10 \mathrm{~mm}$ diameter and $1.5 \mathrm{~mm}$ thickness.

An experienced technician carried out the finishing and polishing sequences in accordance with the manufacturer's instructions. PEEK samples were finished and polished for 1 minute, at a speed of $3000 \mathrm{rpm}{ }^{(13)}$, using PEEK technical kit. Vita Enamic samples finishing and polishing was done using Vita Enamic technical kit at a speed of 7000 rpm with light pressure following manufacturer's instruction. ${ }^{(14,15)}$

The $\mathrm{pH}$ was measured with $\mathrm{pH}$ meter (ADWA AD-11 pH meter). All media were measured 3 times to ensure accuracy of results.

Samples were stored in different $\mathrm{pH}$ solutions according to each subgroup for 24 days in an incubator at $37^{\circ} \mathrm{C}$ which stimulate 2 years of clinical surface. ${ }^{(16)}$ The solutions were changed every 24 hours and fresh solution was prepared each time.

Surface Micro-hardness values of the samples were determined using Digital Display Vickers Micro-hardness Tester (Model HVS-50, Laizhou Huayin Testing Instrument Co., Ltd. China) with a Vickers diamond indenter and a 20X objective lens. A load of $19.6 \mathrm{~N}$ was applied to the surface of the specimens for 15 seconds. Three indentations, which were equally placed over a circle and not closer than $0.5 \mathrm{~mm}$ to the adjacent indentations, were made on the surface of each sample. The diagonal length of the indentations were measured by a built-in scaled microscope and Vickers values were converted into micro-hardness values. Micro-hardness was obtained using the following equation: $H V=1.854$ $\mathrm{P} / \mathrm{d}^{2}$ where, $\mathrm{HV}$ is Vickers hardness in $\mathrm{Kgf} / \mathrm{mm}^{2}, \mathrm{P}$ is the load in $\mathrm{Kgf}$ and $\mathrm{d}$ is the length of the diagonals in $\mathrm{mm}$.

Fracture toughness values were determined by the indentation technique. The basis of the indentation technique is a series of cracks that form under heavy loading in a brittle material around a Vickers diamond indenter. Fracture toughness was determined by the following formula; $\mathrm{K}_{\mathrm{IC}}=0.016(\mathrm{E} / \mathrm{H})^{0.5}\left(\mathrm{P} / \mathrm{c}^{1.5}\right)$ Where $\mathrm{K}_{\mathrm{IC}}$ is the fracture toughness, $\mathrm{C}$ is the crack length (measured from the center of the indentation), $\mathrm{P}$ is the applied indentation load, $\mathrm{H}$ is the Vickers hardness and $\mathrm{E}$ is the elastic modulus. $\mathrm{E}$ for PEEK is $4 \mathrm{GPa}$ while $\mathrm{E}$ for Vita Enamic is $30 \mathrm{GPa}$. Optimal testing load was determined before and after storage by comparing the crack length from the center of the indent to the length of the half diagonal. Digital image analysis system was used to measure the crack length.

Data were presented as mean and standard deviation (SD) values. A regression model with repeated measures ANOVA was used in testing significance for the effect of various $\mathrm{pH}$ media on hardness and fracture toughness. Tukey's post-hoc test was used for pairwise comparison between means when ANOVA showed significant. The significance level was set at $p \leq 0.05$. Statistical analysis was performed with Graph Pad Instat (Graph Pad, Inc.) software for windows.

\section{RESULTS}

Two way ANOVA was performed. Student t-test was done between groups at different $\mathrm{pH}$ media. A value of $\mathrm{P} \leq 0.05$ was considered statistically significant.

\section{Hardness:}

For group PEEK, it was found that baseline subgroup recorded the statistically significant highest hardness mean value $(232.53 \pm 3.6 \mathrm{HV})$ followed by pH 5.5 subgroup mean value $(229.33 \pm 4.8 \mathrm{HV})$, then $\boldsymbol{p H} 7$ subgroup mean $(227.88 \pm 5.6 \mathrm{HV})$, while $\boldsymbol{p H}$ 2.5 subgroup recorded the statistically significant lowest hardness mean value $(222.60 \pm 5.2 \mathrm{HV})$ as indicated by two-way ANOVA test $(\mathrm{p}=0.0008<$ $0.05)$. Pair-wise Tukey's post-hoc test showed nonsignificant difference between (baseline and $\boldsymbol{p H}$ 5.5), (baseline and $\mathrm{pH} \mathrm{7)} \mathrm{and} \mathrm{(pH} 5.5$ and $p H$ 7) subgroups (Table 1). 
For group Vita Enamic, it was found that baseline subgroup recorded the statistically non- significant highest hardness mean value $(242.01 \pm 5.08$ HV), followed by $\boldsymbol{p H} 5.5$ subgroup mean value $(230.31 \pm 2.56 \mathrm{HV})$, then $\boldsymbol{p H} \mathbf{7}$ subgroup mean (230.05 $\pm 2.87 \mathrm{HV}$ ), while $\boldsymbol{p} \boldsymbol{H} \mathbf{2 . 5}$ subgroup recorded the statistically non-significant lowest hardness mean value $(228.46 \pm 2.63 \mathrm{HV})$ as indicated by oneway ANOVA test $(\mathrm{p}=.0924>0.05)($ Table 1$)$.

Table (1): Descriptive statistics of hardness results (Mean values \pm SDs) for both groups at different $\mathrm{pH}$ media

\begin{tabular}{|c|c|c|c|c|c|}
\hline \multirow{2}{*}{ 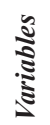 } & \multirow{2}{*}{ pH_Media } & \multirow{2}{*}{$\operatorname{Mean} \pm S D$} & \multicolumn{2}{|c|}{$95 \% \mathrm{CI}$} & \multirow{2}{*}{$\begin{array}{c}\text { Statistics } \\
\text { P value }\end{array}$} \\
\hline & & & Low & High & \\
\hline \multirow{4}{*}{ 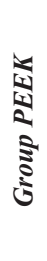 } & Baseline & $232.53 \pm 3.6$ & 230.12 & 234.88 & \multirow{4}{*}{$0.0008 *$} \\
\hline & pH_5.5 & $229.33 \pm 4.8$ & 225.89 & 232.77 & \\
\hline & $p H \_2.5$ & $222.60 \pm 5.2$ & 218.87 & 226.33 & \\
\hline & pH_7 & $227.88 \pm 5.6$ & 223.86 & 231.89 & \\
\hline \multirow{4}{*}{ 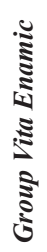 } & Baseline & $242.01 \pm 5.08$ & 238.11 & 245.91 & \multirow{4}{*}{$0.0924 \mathrm{~ns}$} \\
\hline & pH_5.5 & $230.31 \pm 2.56$ & 228.48 & 232.14 & \\
\hline & $p H \_2.5$ & $228.46 \pm 2.63$ & 226.57 & 230.34 & \\
\hline & pH_7 & $230.05 \pm 2.87$ & 227.99 & .1232 & \\
\hline
\end{tabular}

*; significant $(p<0.05)$

$n s ;$ non-significant $(p>0.05)$

\section{Fracture toughness}

For group PEEK, it was found that baseline subgroup recorded the statistically significant highest fracture toughness mean value $(1.859 \pm 0.24$ MPa. $\left.{ }^{0.5}\right)$, followed by $\boldsymbol{p} \boldsymbol{H} \mathbf{7}$ subgroup mean value $\left(1.315 \pm 0.08 \mathrm{MPa} . \mathrm{m}^{0.5}\right)$, then $\boldsymbol{p H} \mathbf{2 . 5}$ subgroup mean $\left(1.294 \pm 0.32 \mathrm{MPa} . \mathrm{m}^{0.5}\right)$, while $\boldsymbol{p H} 5.5$ subgroup recorded the statistically significant lowest fracture toughness mean value $\left(1.106 \pm 0.09 \mathrm{MPa}^{0.5}\right)$ as indicated by one-way ANOVA test $(\mathrm{p}=0.0003<0.05)$. Tukey's post-hoc test showed non-significant ( $>0.05)$ difference between different $\mathrm{pH}$ media (Table 2).
For group Vita Enamic, it was found that baseline subgroup recorded statistically significant highest fracture toughness mean value $(1.383 \pm 0.36$ MPa.m ${ }^{0.5}$ ), followed by $\boldsymbol{p H} \mathbf{5 . 5}$ subgroup mean value $\left(1.088 \pm 0.14 \quad \mathrm{MPa} \cdot \mathrm{m}^{0.5}\right)$, then $\boldsymbol{p H} \_2.5$ subgroup mean $\left(0.969 \pm 0.12 \mathrm{MPa} \cdot \mathrm{m}^{0.5}\right)$, while $\boldsymbol{p} \boldsymbol{H} \_7$ subgroup recorded the statistically non-significant lowest fracture toughness mean value $(0.958 \pm 0.13$ $\left.\mathrm{MPa} \cdot \mathrm{m}^{0.5}\right)$ as indicated by one-way ANOVA test $(\mathrm{p}=0.0143<0.05)$. Tukey's post- hoc test showed non-significant $\quad(\mathrm{p}>0.05)$ difference between (baseline and $\boldsymbol{p H}$ _7) and between different $p H$ media (Table 2).

Table (2): Descriptive statistics of fracture toughness results (Mean values \pm SDs) for both groups at different $\mathrm{pH}$ media

\begin{tabular}{|c|c|c|c|c|c|}
\hline \multirow{2}{*}{$\frac{\sqrt{0}}{\sqrt[3]{5}}$} & \multirow{2}{*}{ pH_Media } & \multirow{2}{*}{ Mean $\pm S D$} & \multicolumn{2}{|c|}{$95 \% C I$} & \multirow{2}{*}{$\begin{array}{c}\text { Statistics } \\
\text { P value }\end{array}$} \\
\hline & & & Low & High & \\
\hline \multirow{4}{*}{ 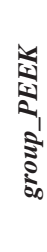 } & Baseline & $1.859 \pm 0.24$ & 1.563 & 2.155 & \multirow{4}{*}{$0.0003^{*}$} \\
\hline & $p H \_5.5$ & $1.106 \pm 0.09$ & 0.990 & 1.222 & \\
\hline & $p H \_2.5$ & $1.294 \pm 0.32$ & 0.903 & 1.685 & \\
\hline & pH_7 & $1.315 \pm 0.08$ & 1.211 & 1.419 & \\
\hline \multirow{4}{*}{ 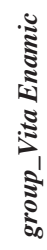 } & Baseline & $1.383 \pm 0.36$ & 0.995 & 1.770 & \multirow{4}{*}{$0.0143 *$} \\
\hline & $p H_{-} 5.5$ & $1.088 \pm 0.14$ & 0.934 & 1.241 & \\
\hline & $p H \_2.5$ & $0.969 \pm 0.12$ & 0.837 & 1.101 & \\
\hline & $p H \_7$ & $0.958 \pm 0.13$ & 0.828 & 1.089 & \\
\hline
\end{tabular}

*; significant $(p<0.05)$

$n s$; non-significant ( $p>0.05)$

\section{DISCUSSION}

It was reported that PEEK has good mechanical properties and modulus of elasticity similar to dentin that can lead to close interaction between the polymeric component of the material and dental tissues, which allows good distribution of forces between a PEEK restoration and an abutment tooth ${ }^{(7)}$. PEEK is considered as an alternative material to a metal framework, which is currently might not be 
accepted by patients. This material is veneered by reinforced composite in order to obtain maximum esthetics, besides its high mechanical properties ${ }^{(5,6)}$.

Vita Enamic is a monolithic form of polymerbased restorations which is considered a hybrid dental ceramic with dual network structure that provides minimal invasive restoration. Vita Enamic was reported to have high flexural strength values and elasticity resembling to dentine ${ }^{(8,17)}$. Vita Enamic can be used as an inlay, onlay, laminate veneers and anterior and posterior crowns.

Fracture toughness is widely accepted as a parameter for assessment of the reliability of ceramic materials. Fracture toughness of the material is not only a measure of its ability to retard crack propagation, but it is also important for the prevention of marginal breakdown and is possibly related to good wear resistance, recent studies found that the fracture toughness is the measure of the wear of the opposing because if the material is not tough to resist fracture ,brittle chipping may occur this can abrade the surface of the antagonist and increase the wear rate ${ }^{(18,19)}$.

Hardness is one of the most important properties when comparing dental materials as it measures the resistance to surface penetration or indentation. The significance of hardness measurement in restorative dentistry is that it delineates the abrasiveness of restorative material to which the natural dentition may be submitted ${ }^{(20)}$.

The American society for testing defined that Vickers hardness measurement covered the requirements of standard test methods ${ }^{(21)}$. The thickness of the discs allow the indentation depth without fracture of samples during Vickers hardness test because the sample must be have minimal thickness at least (ten times) the indentation depth which is expected to be attained ${ }^{(21)}$.

In this study, samples were stored in different storage media in an incubator at 37C for 24 hours which stimulate 2 years of clinical surface ${ }^{(16)}$. The choice of different $\mathrm{pH}$ storage media was attributed to the oral cavity which is a complex, aqueous environment where the dental material is in contact with saliva and it subjected to fluctuation in $\mathrm{pH}$ due to consumption of different beverages and foods such as tea, coffee, soft drinks, alcoholic beverage and even fluoridated water that have been reported to affect the mechanical properties and esthetic of the restoration while in service ${ }^{(22)}$.

The reason behind that the materials were affected by different $\mathrm{pH}$ media related to the low $\mathrm{pH}$ of Pepsi (2.5) cause surface erosion that weakens the matrix-filler bonding, resulting in bond failures in the outer layer of the filler that lead to decreasing the hardness and eventually lowers the fracture toughness of the material ${ }^{(23)}$. In vivo studies ${ }^{(24,25)}$ indicate that the exposure of resin composites to low $\mathrm{PH}$ liquid can negatively affect their mechanical properties.

On the other hand, coffee is mainly composed of water and the effect of water uptake can degrade polymer materials ${ }^{(26)}$.

Vita Enamic is composed of polymer $14 \%$ by weight urethane dimethacrylate (UDMA) and triethylene glycol dimethacrylate (TEGDMA) and $86 \%$ of ceramics. This polymeric material absorbs water, thus coupling agent undergoes hydrolysis and consequently loss chemical bond between resin matrix and filler particles, the filler particles dislodge from the outer surface of the material causing surface roughness and consequently decrease hardness and eventually fracture toughness ${ }^{(27)}$.

PEEK material has composite as a veneering material, which has a resin type different from the resin of Vita Enamic material. The type of resin is a contributing factor in water sorption.

Vita Enamic showed higher hardness than PEEK. This may be due to the effect of composite veneering of PEEK while vita Enamic is a monolithic material with more ceramic content. In the opposite side group PEEK recorded higher fracture toughness 
than group Vita Enamic, may be due to the effect of sub base layer of PEEK material that have low modulus of elasticity that can absorb indentation load while vita Enamic is a monolithic material.

The results of the present study were supported by, Gharatkar et al, ${ }^{(28)}$ who studied the effect of cola, orange juice and wine on surface micro hardness of Nano composite. Micro hardness tester was used to evaluate surface micro hardness of circular discs. They found a significant decrease in mean value of Vickers hardness number after immersion.

Also supported by Saba et al, ${ }^{(29)}$ who evaluated and compared the effect of common beverages (coffee, red wine and distilled water) on micro hardness of CAD/CAM hybrid (Vita Enamic) versus Feldspathic (Vita Mark II). Vickers micro hardness tester was used to evaluate surface micro hardness. They found a significant decrease in micro hardness of both EN an VM when immersed in coffee and this change was no significantly different between two materials.

Vickers hardness values of Vita Enamic measured before and after immersion in different solution were significantly lower than those of VM. So it was concluded that coffee may adversely affect micro hardness of EN and VM.

It was recommended that this study can add cyclic loading to become more valuable.

\section{CONCLUSIONS}

Within the limitations of this study, it was concluded that:

1. PEEK recorded higher fracture toughness mean value than Vita Enamic.

2. Vita Enamic recorded higher hardness mean value than PEEK.

3. Both materials were affected more by $\mathrm{pH} 2.5$ (Pepsi), followed by pH5.5 (coffee), then $\mathrm{pH} 7$ when measuring hardness.
4. Both materials were affected more by $\mathrm{pH} 5.5$ (coffee), followed by $\mathrm{pH} 2.5$ (Pepsi), then by $\mathrm{pH} 7$ when measuring fracture toughness.

\section{REFERENCES}

1. Kelly JR, Nishimura I, Campbell SD. Ceramics in dentistry: historical roots and current perspectives. J. prosthet. Dent. 1996;75(1):18-32.

2. Toth JM, Wang M, Estes BT, Scifert JL, Seim III HB, Turner AS. Polyetheretherketone as a biomaterial for spinal applications. Biomat. 2006;27(3):324-34.

3. Kurtz SM, Devine JN. PEEK biomaterials in trauma, orthopedic, and spinal implants. Biomat. 2007;28(32):4845-69.

4. Pokorný D, Fulin P, Slouf M, Jahoda D, Landor I, Sosna A. Polyetheretherketone (PEEK). Part II: Application in clinical practice. Acta. Chir. Tr. 2010;77(6):470-8.

5. Stawarczyk B, Beuer F, Wimmer T, Jahn D, Sener B, Roos M, et al. Polyetheretherketone-a suitable material for fixed dental prostheses? J. Biomed. Mater. Res. B. 2013;101(7):1209-16.

6. Stawarczyk B, Jordan P, Schmidlin PR, Roos M, Eichberger M, Gernet W, et al. PEEK surface treatment effects on tensile bond strength to veneering resins. J. prosthet. Dent. 2014;112(5):1278-88

7. Rees J, Jacobsen P. The elastic moduli of enamel and dentine. Clinic.Mater.1993;14(1):359

8. Ruse N, Sadoun M. Resin-composite blocks for dental CAD/ CAM applications. J. Dent. Res. 2014;93(12):1232-4.

9. Dirxen C, Blunck U, Preissner S. Clinical performance of a new biomimetic double network material. Open Dent. J. $2013 ; 7: 118$.

10. Taira M, Nomura Y, Wakasa K, Yamaki M, Matsui A. Studies on fracture toughness of dental ceramics. Journal of oral rehabilitation. 1990;17(6):551-63.

11. Sinha N, Gupta N, Reddy KM, Shastry Y. Versatility of PEEK as a fixed partial denture framework. J. Indian Prosthodont. Soc. 2017;17(1):80.

12. Thomé T, Erhardt MC, Leme AA, Al Bakri I, BedranRusso AK, Bertassoni LE. Emerging polymers in dentistry. Advanced polymers in medicine: Springer; 2015. p. 265-96.

13. Heimer S, Schmidlin PR, Roos M, Stawarczyk B. Surface properties of polyetheretherketone after different laboratory and chairside polishing protocols. J. Prosthet. Dent. 2017;117(3):419-25. 
14. Sarkkaya I, Yerliyurt K, Hayran Y. Effect of surface finishing on the colour stability and translucency of dental ceramics. BMC oral health. 2018;18(1):40.

15. Özarslan MM, Büyükkaplan UŞ, Barutcigil Ç, Arslan M, Türker N, Barutcigil K. Effects of different surface finishing procedures on the change in surface roughness and color of a polymer infiltrated ceramic network material. J .Adv. Prosthodont. 2016;8(1):16-20.

16. Lawson NC, Burgess JO. Gloss and stain resistance of ceramic-polymer CAD/CAM restorative blocks. J. Esthet. Restor. Dent. 2016;28:S40-S5.

17. Wegner L, Gibson L. The fracture toughness behaviour of interpenetrating phase composites. Int. J. Mech. Sci. 2001;43(8):1771-91.

18. Seghi R, Rosenstiel S, Bauer P. Abrasion of human enamel by different dental ceramics in vitro. J. Dent. Res. 1991;70(3):221-5.

19. Mackert Jr J, Williams A. Microcracks in dental porcelain and their behavior during multiple firing. J. Dent. Res. 1996;75(7):1484-90.

20. Heberling T, Fee A, Tobolski E. Minimum thickness requirements for Rockwell hardness testing. J. Test. Eval. 1996;24(2):131-9.

21. Nunn JH. Prevalence of dental erosion and the implications for oral health. Eur. J. Oral Sci. 1996;104(2):156-61.

22. Zhang Y, Chai H, Lawn BR. Graded structures for all-ceramic restorations. J. Dent. Res. 2010;89(4):417-21.
23. Güngör M, Artunç C, Sonugelen M. Parameters affecting retentive force of conus crowns. Journal of oral rehabilitation. 2004;31(3):271-7.

24. Staniland P, Wilde C, Bottino F, Di Pasquale G, Pollicino A, Recca A. Synthesis, characterization and study of the thermal properties of new polyarylene ethers. Polymer. 1992;33(9):1976-81 .

25. Skinner HB. Composite technology for total hip arthroplasty. Clinic. Orthop. Relat. Res. 1988(235):224-36.

26. Lee WT, Koak JY, Lim YJ, Kim SK, Kwon HB, Kim MJ. Stress shielding and fatigue limits of poly-ether-etherketone dental implants. Journal of Biomedical Materials Research Part B: Applied Biomaterials. 2012;100(4): 1044-52.

27. Schmidlin PR, Stawarczyk B, Wieland M, Attin T, Hämmerle $\mathrm{CH}$, Fischer J. Effect of different surface pretreatments and luting materials on shear bond strength to PEEK. Dent. Mat. 2010;26(6):553-9.

28. Gharatkar AA, Irani R, Shiraguppi V, Hegde V. Effect of cola, orange juice, and wine on surface micro-hardness of nano-composites: an in vitro study. J .Dent. Orofac. Res. 2014;10(1):16-20

29. Saba DA, Salama RA, Haridy R. Effect of different beverages on the color stability and microhardness of CAD/ CAM hybrid versus feldspathic ceramic blocks: An invitro study. Future. Dent. J. 2017;3(2):61-6. 